\title{
Nephroureterectomy with Cuff of Bladder
}

National Cancer Institute

\section{Source}

National Cancer Institute. Nephroureterectomy with Cuff of Bladder. NCI Thesaurus.

Code C159437.

Surgical resection of the kidney, renal pelvis, ureter, and bladder cuff. 